\title{
The Nutritional Fatty Acids Profile and Physicochemical Properties of Canarium indicum Nut Oil
}

\author{
Rahman $\mathrm{H}^{1,2^{*}}$, Tursino ${ }^{2}$, Sitompul J P ${ }^{3}$, Anggadiredja $\mathrm{K}^{2}$, Gusdinar $\mathrm{T}^{2}$ \\ ${ }^{I}$ Faculty of Public Health, Muhammadiyah University of North Moluccas, Indonesia \\ ${ }^{2}$ Department of Pharmacy, School of Pharmacy, Institute of Technology Bandung \\ ${ }^{3}$ Department of Chemical Engineering, Faculty of Industrial Technology, \\ Institute of Technology Bandung, Bandung 40132, Indonesia
}

Available Online: $21^{\text {st }}$ November, 2015

\begin{abstract}
Canarium indicum nut produce vegetable oil which comprised of triglycerides with fatty acids composition. In this paper, mechanical pressing and solvent extraction methods were performance to extract oils of Canarium indicum nut. Fatty acids profile of Canarium indicum oils were determined using high-performance liquid chromatography. In addition, physicochemical properties were determined to assess quality of oils. The fatty acids composition showed that Canarium indicum oils were rich in unsaturated fatty acids, $86.14 \%$ and $90.27 \%$ for mechanical pressing and solvent extraction, respectively. Both of Canarium indicum oils were similar in term of physicochemical properties. Overall, the results of this study designate that Canarium indicum oils are eligible to be used as a source of edible oil and can be utilized as raw material for medical, nutraceutical and other food applications.
\end{abstract}

Keywords : Canarium indicum nut, edible oil, fatty acids, physicochemical properties of oil.

\section{INTRODUCTION}

Canarium indicum (C. indicum) is a species of canarium that belongs to Burseracea family. Canarium is a native plant to eastern part of Indonesia, Papua New Guinea, the Solomon Islands and Vanuatu ${ }^{1,2}$. In Indonesia, canarium tree are underutilized and not yet widely cultivated, thus it is still has a low economic value. The kernel of $C$. indicum (figure 1) may contain up to $75 \% \mathrm{oil}^{3}$, therefore it can be used as a source of vegetable oil. Based on this, canarium nut are comparable to other tree nuts with high oil content, namely almond, cashew, walnut, Brazil nuts, hazelnuts, pecans, and macadamia ${ }^{2}$. According to epidemiological report, the emulsion of well-ripe seeds of $C$. indicum may be used as milk substitute for infants ${ }^{3,}{ }^{4}$, means that canarium seed is non-toxic and secure to be utilized in food applications. The nutritional value and oil quality for nutraceutical and food applications are specified by composition of fatty acids on triglycerides, as well as by physicochemical properties of the oil. The objective of this study is to determine fatty acid composition and physicochemical properties of C.indicum oils extracted by two extraction methods to assess potency of Canarium indicum oil for nutritional applications and for other applications of the pharmaceutical field.

\section{MATERIALS AND METHODS}

Materials: Canarium nut of $C$. indicum species were taken and collected from a tree grown in Halmahera region, North Moluccas (Indonesia). The plant of $C$. indicum was identified by Indonesian Institute of Sciences. The nut were grounded and dried in an oven at $40^{\circ} \mathrm{C}$ until water content reached of $2 \%$. The standard of fatty acids (caprylic and capric) were purchased from Sigma-Aldrich, while lauric, myristic, palmitic, palmitoleic, stearic, oleic, linoleic, and linolenic were purchased from Nacalai tesque. Acetonitrile, chloroform, n-hexane and methanol were either high-performance lipid chromatography (HPLC) or analytical grade obtained from commercial sources.

Extraction of canarium oils

Extraction methods to obtain canarium oils were conducted by using a mechanical pressing equipped with hydraulic presses, while solvent extraction was performance by soxhlet apparatus. The mechanical pressing extraction was carried out by placing as many as $600 \mathrm{~g}$ of ground seed in the apparatus. Pressing was done mechanically using a constant pressure in the press tool and performed at ambient temperature. Canarium oil was collected for further analysis. The solvent extraction was prepared for $30 \mathrm{~g}$ of ground seed of canarium and $250 \mathrm{~mL}$ of $n$-hexane. The extraction was conducted for $8 \mathrm{~h}$ or until solvent extraction have seen clear. The solvent was evaporated in vacuum evaporator, and canarium oil was collected for further analysis.

Fatty acids analysis

Saponification of canarium oils was carried prior to determination of total fatty acids on triglyceride, based on the method that has been done by $\mathrm{Chen}^{5}$. Sodium hydroxide solution was prepared by dissolving $48 \mathrm{~g}$ of sodium hydroxide and $0.5 \mathrm{~g} \mathrm{Na}_{2}$ EDTA in $160 \mathrm{~mL}$ of water, 
then added $160 \mathrm{~mL}$ of ethanol. A mixture of $100 \mathrm{~g}$ oil and $200 \mathrm{~mL}$ of sodium hydroxide was heated at $60^{\circ} \mathrm{C}$ for $1 \mathrm{~h}$ with magnetic stirring at $550 \mathrm{rpm}$. Subsequently, $40 \mathrm{~mL}$ of water and $400 \mathrm{ml}$ of $\mathrm{n}$-hexane was added and stirred for 1 h. The upper layer (unsaponifiable portion) was separated for further analysis. The lower layer portion was added 160 $\mathrm{mL}$ of water and $12 \mathrm{~N}$ hydrochloric acid until the mixture reaches a $\mathrm{pH} 1$. Finally, the solution was separated in a separating funnel. The upper layer contains free fatty acids was taken. The remaining water was dried with anhydrous sodium sulfate.The solvent was then evaporated under nitrogen and subsequently the fatty acids fraction was derivatized to form $\mathrm{p}$-bromophenacyl esters following HPLC analysis.

Analysis of fatty acids composition with HPLC based on the procedure by Arcos et al. ${ }^{6}$, with some modifications. Analysis systems were achieved with a Hitachi D-7000 and coupled to an ultraviolet detector at wavelength 254 $\mathrm{nm}$. The fatty acids were separated with a Luna $5 \mu \mathrm{C} 8$ (2) $100 \mathrm{~A}$ column $(0.15 \mathrm{~m} \times 4.6 \mathrm{~mm})$ and the column oven temperature was ambient temperature. The mobile phase was acetonitril/water $(87: 13, \mathrm{v} / \mathrm{v})$ with a constant mobile phase flowrate of $1.5 \mathrm{~mL} / \mathrm{min}$ and the injection volume was $20 \mu \mathrm{L}$. The derivatization was conducted before analysis by changing the fatty acids to p-bromophenacyl esters. Approximately $100 \mu \mathrm{L}$ of a $0.5 \mathrm{mg} / \mathrm{mL}$ solution of 18-crown-6-ether in acetonitrile was added to $3 \mathrm{~mL}$ of a solution containing $0.15 \mathrm{mg} / \mathrm{mL}$ of PBPB in acetonitrile. Next, $300 \mu \mathrm{L}$ of solution containing the fatty acids was combined with the mixture of PBPB and 18-crown-6-ether together with approximately $200 \mathrm{mg}$ of $\mathrm{K}_{2} \mathrm{CO}_{3}$. The mixture was held at $80^{\circ} \mathrm{C}$ in a sealed vial for $30 \mathrm{~min}$ and then cooled in an ice bath for $15 \mathrm{~min}$. Finally, the mixture was filtered through a $0.45 \mu \mathrm{m}$ membrane filter and then analyzed by HPLC.

\section{Physicochemical properties analysis}

Physicochemical parameters such as refractive index, saponification value, iodine value, free fatty acids and unsaponifiable matter were analyzed by standard AOCS methods ${ }^{7}$.

Statistical analysis: Fatty acids identification of canarium oil was carried out by comparing the chromatographic peak of fatty acids standard based on the retention time and the values was expressed as mole percentage (mole \%). All analytical determination were performed in triplicate and reported as mean \pm standard deviation.

\section{RESULTS AND DISCUSSION}

Mechanical pressing as well as solvent extraction has traditionally used to extract oils which comprised of triglycerides. In this study, the yields extraction of mechanical pressing and solvent extraction was $61.36 \%$ and $30.20 \%$, respectively. Mechanical pressing extraction is preferred for samples with high oil content because it is more economical. Typically, both extraction methods were combined to gain maximum yield based on economical values $^{8,9}$. The results showed that the oil yield was greater of the mechanical pressing $(61.36 \%$ ) compared with solvent extraction $(30.20 \%)$. The other advantage of mechanical pressing is there are no solvent residues.

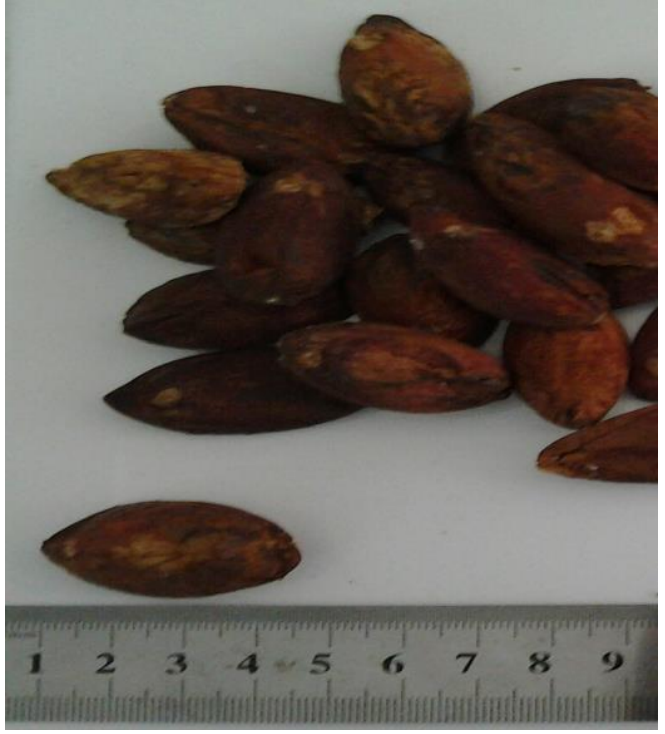

Fig 1: Canarium indicum nut.

Furthermore, the composition of fatty acids on canarium oils is summarized in Table 1 with HPLC chromatograms of each fatty acid in figure 2 . Generally, tree nuts such as almond, hazelnuts, walnut, and cashew are rich in monounsaturated fatty acids, predominantly oleic acid, and also contain much lower amounts of polyunsaturated fatty acids, predominantly linoleic acid and small amount of saturated fatty acids ${ }^{9}$. As shown in table 1, fatty acids on canarium oils were oleic acid (51.99 and 50.73\%), linoleic acid (32.97 and 38.01\%), and palmitic acid (9.82 and 6.21) extracted from mechanical pressing and solvent extraction, respectively. By comparing to some tree nut oils (as shown in Table 2), largely, tree nut oils contain fatty acids which the highest are oleic acid, linoleic acid and palmitic acid, respectively, as well as on canarium oil as reported in this study. The nutritional value of oleic acid has been reported by some researcher. Oleic acid has been shown to be neutral with regard to plasma lipids; hence it is a source for food formulations ${ }^{10}$, as well as few studies have reported the role of oleic acid in reducing cholesterol plasma ${ }^{11,12}$. Supplements rich unsaturated fatty acids such as oleic acid and linoleic acid derived from olive oil could be used to prevent coronary heart disease ${ }^{13}$. Besides providing energy, fat intake is as well necessary to supply the human body with essential fatty acids (EFA). Linoleic acid (C18:2n6) and linolenic acid (C18:3n3) are an essential fatty acids that could not be synthesized on humans, therefore humans need to consume from outside ${ }^{14}$, for example from plants source. They are essential components of the cell membrane structure and as a precursor for biologically active metabolites, namely eicosanoics ${ }^{15}$. Linoleic acid can be desaturated and elongated to arachidonic acid (ARA), meanwhile linolenic acid is converted to eicosapentaenoic acid (EPA) and docosahexaenoic acid (DHA) ${ }^{11,14}$. ARA and DHA are well-known as substance to encourage the development of brain nervous cell while EPA can decreases blood viscosity and reduce hypercholesterolemia ${ }^{15}$, ${ }^{16}$. The analysis results of physicochemical properties of canarium oils extracted by two extraction methods summarized in Table 3 . The saponification value is the amount of alkali 

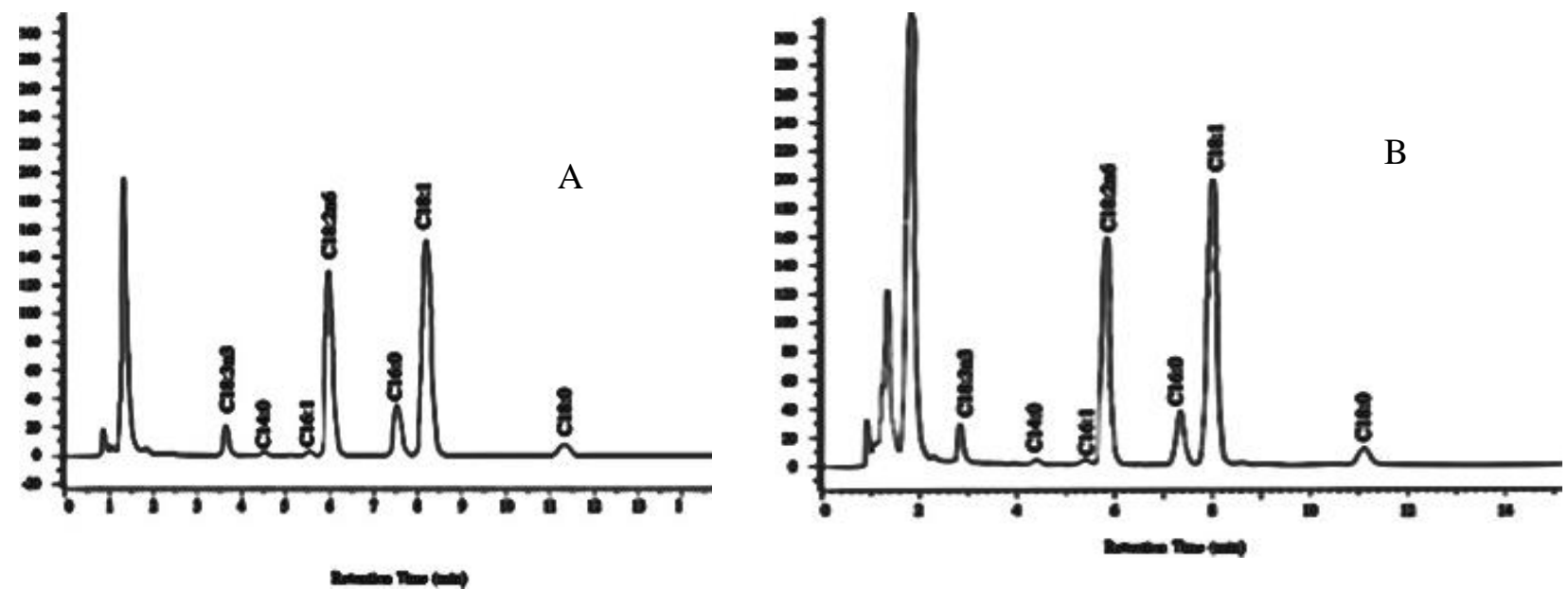

Fig 2: Fatty acid chromatograms of canarium oils, (A) from mechanical pressing, and (B) from solvent extraction

Table 1: The fatty acid composition of $C$. indicum oil extracted using different methods (mole $\%$ )

\begin{tabular}{lcc}
\hline Fatty acids & Mechanical pressing & Soxhlet \\
\hline Myristic $\left(\mathrm{C}_{14: 0}\right)$ & $0.05 \pm 0.02$ & $0.05 \pm 0.02$ \\
Palmitic $\left(\mathrm{C}_{16: 0}\right)$ & $9.82 \pm 0.38$ & $6.21 \pm 0.83$ \\
Stearic $\left(\mathrm{C}_{18: 0}\right)$ & $4.03 \pm 0.46$ & $3.47 \pm 0.51$ \\
Palmitoleic $\left(\mathrm{C}_{16: 1}\right)$ & $0.64 \pm 0.13$ & $0.90 \pm 0.23$ \\
Oleic $\left(\mathrm{C}_{18: 1}\right)$ & $51.99 \pm 0.99$ & $50.73 \pm 0.56$ \\
Linoleic $\left(\mathrm{C}_{18: 2 \mathrm{n} 6}\right)$ & $32.97 \pm 0.91$ & $38.01 \pm 0.73$ \\
Linolenic $\left(\mathrm{C}_{18: 3 n 3}\right)$ & $0.54 \pm 0.06$ & $0.63 \pm 0.12$ \\
Total SFA & 13.90 & 9.73 \\
Total MUFA & 52.63 & 51.63 \\
Total PUFA & 33.51 & 38.64 \\
\hline
\end{tabular}

SFA: saturated fatty acids; MUFA: monounsaturated fatty acids; PUFA: polyunsaturated fatty acids

Table 2: The comparison of fatty acids profile of canarium oil with that of some tree nuts oils $(\%)$

\begin{tabular}{lccccc}
\hline Tree nuts & $\mathrm{C}_{18: 1}$ & $\mathrm{C}_{18: 2 \mathrm{n} 6}$ & $\mathrm{C}_{16: 0}$ & $\mathrm{C}_{18: 0}$ & $\mathrm{C}_{16: 1}$ \\
\hline *Almond oil & 68 & 25 & 4.7 & 2 & 2 \\
*Hazelnut oil & 78 & 9 & 4 & 2 & 2 \\
*Pecan oil & 55 & 33 & 7 & 2 & $\mathrm{n} \mathrm{r}$ \\
*Walnut oil & 26 & 63 & 7 & 2 & $\mathrm{n} \mathrm{r}$ \\
*Brazil nut oil & 48 & 30 & 15 & 6 & $\mathrm{n} \mathrm{r}$ \\
*Cashew oil & 57 & 18 & 9 & $\mathrm{n} \mathrm{r}$ & $\mathrm{n} \mathrm{r}$ \\
**Canary oil & 51 & 32 & 9 & 4 & 0.64 \\
\hline$*$ reference $(9)$ & **: presen study & & $\mathrm{n} \mathrm{r}:$ not reported & &
\end{tabular}

$*$ : reference $(9) \quad * *$ : present study

(in mg of potassium hydroxide) that necessary to saponify of oil. Saponification value can indicate an average molecular weight of triglyceride of oils ${ }^{8,9}$. High saponification value indicates low molecular weight fatty acids ${ }^{17}$ or predominantly portion of short chain fatty acids on triglycerides. Saponification value of canarium oils was 174 and $180 \mathrm{mg} \mathrm{KOH} / \mathrm{g}$, which was lower compared to palm oil (200.65 mg KOH/g) $)^{18}$ and coconut oil $(246.28 \mathrm{mg}$ $\mathrm{KOH} / \mathrm{g})^{19}$ and similar with almond oil $(189 \mathrm{mg} \mathrm{KOH} / \mathrm{g})^{9}$. The saponification value of canarium oil indicated that high molecular weight fatty acids were contained on canarium oil.

The unsaponifiable matter refers to components that is soluble in oil but cannot be saponified such as aliphatic n r: not reported

alcohols, sterols, pigments and hydrocarbons ${ }^{8,} 9$. Unsaponifiable matter are also can be used to authenticate oils and detect adulteration ${ }^{9}$. The unsaponifiable matter was higher in canarium oil extracted by solvent extraction $(0.21 \%)$ compared to mechanical pressing method $(0.11 \%)$. This is due to the ability of solvent to extract nonpolar substances than just by mechanical pressing. Iodine value is a measure for the average number of double bonds of oil or $\mathrm{fat}^{8}$ and based on all unsaturated components in the oil ${ }^{17}$. The iodine value of solvent extraction (98.23) was higher than oil of mechanical pressing (90.69). The difference of these values was due to the differences of unsaponified matters in both oils. The unsaponifiable matter may contain antioxidants which 
Table 3: Physicochemical properties of Canarium indicum oil extracted using different methods

\begin{tabular}{lcc}
\hline $\begin{array}{l}\text { Physicochemical } \\
\text { Properties }\end{array}$ & $\begin{array}{c}\text { Mechanical } \\
\text { pressing }\end{array}$ & Soxhlet \\
\hline $\begin{array}{l}\text { Saponification value } \\
(\mathrm{mg} \mathrm{KOH} / \mathrm{g})\end{array}$ & $175.47 \pm 0.83$ & $180.05 \pm 0.73$ \\
$\begin{array}{l}\text { Unsaponifiable } \\
\text { matter }(\mathrm{g} \%)\end{array}$ & $0.11 \pm 0.01$ & $0.21 \pm 0.01$ \\
$\begin{array}{l}\text { Iodine value (g } \\
\text { iodine } / 100 \mathrm{~g} \text { of fat) }\end{array}$ & $90.69 \pm 1.68$ & $98.23 \pm 2.30$ \\
$\begin{array}{l}\text { Free fatty acids }(\% \\
\text { oleic acid) }\end{array}$ & $0.39 \pm 0.05$ & $0.53 \pm 0.02$ \\
$\begin{array}{l}\text { Refractive index (at } \\
\left.40{ }^{\circ} \mathrm{C}\right)\end{array}$ & $1.47 \pm 0.001$ & $1.45 \pm 0.002$ \\
$\begin{array}{l}\text { Yield extraction }(\% \\
\text { weight) }\end{array}$ & $61.36 \pm 2.31$ & $30.20 \pm 1.20$ \\
\hline
\end{tabular}

have double bond structures allowing canarium oil has a high oxidative stability. Compare with most other vegetable oils, generally tree nut oils show high oxidative stability, which is due to high level of monounsaturated fatty acids rather than polyunsaturated fatty acids and high concentrations of minor components with antioxidant activity ${ }^{9}$. Free fatty acid is one of the main criteria for checking quality of edible oil and indicates a higher level of oil hydrolysis ${ }^{20}$. Free fatty acid value of oil extracted by mechanical pressing was $0.11 \%$, while from solvent extraction was $0.21 \%$. These values were quite lower because both oils were processed freshly. Refractive index is an important optical parameter to analyze the light rays traversing through materials medium and can be used as a tool for determinate the adultration of oils ${ }^{21}$. The values of refractive index of canarium oil were 1.47 and 1.45 for canarium oil extracted by mechanical pressing and solvent extraction, respectively. These values were eligible as edible oil.

\section{CONCLUSIONS}

The fatty acids profile of canarium oils shows similar to some tree nut oils with the highest compositions was oleic acid, linoleic acid and palmitic acid, respectively. The fatty acids on canarium oils have good nutritive value with predominantly of monounsaturated fatty acids (oleic acid and palmitoleic), polyunsaturated fatty acids (linoleic and linolenic) and saturated fatty acid (myristic, palmitic, stearic). The results study of physicochemical properties show that canarium oil can be considered as a source of edible oil, to diversify the sources of vegetable oils, especially from tree nut oils that have been used previously. In addition, the data of this study provide information on the characterization of $C$. indicum oil which are lacking in the literature.

\section{ACKNOWLEDGEMENTS}

This work was financed by the Ministry of Research Technology and Higher Education of Indonesia (project No.368/K12/KM/2015) and Institute of Technology Bandung through Research and Innovation Department, and supported by Korea Research of Bioscience and Biotechnology (KRIBB) of the Republic of Korea.

\section{REFERENCES}

1. Thomson LAJ, Evans B. Species profiles for Pasific island agroforestry, Canarium indicum var indicum and C. Harveyi. Downloaded from: www.traditionaltree.org on 9/9/2014, 2006.

2. Gregoria SSD, Erny JNN, Maria FS, Lana EL. Analysis of bioactive compound in canarium nut (Canarium indicum L). Downloaded from: https://seafast.ipb.ac.id/tpc-project/analysis-ofbioactive-compound-in-canarium-nut-canariumindicum-1/ on 9/1/2013, 2011.

3. Pre-market notification new dietary ingredient notification Canarium indicum nut oil. Downloaded from: https:// http://www.fda.gov/ohrms/dockets/dockets/95s0316/9 5s-0316-rpt0289-04-vol227.pdf on 9/9/2014.

4. Heyne K. The Useful Plants of Indonesia. Sarana Wana Jaya Foundation, Jakarta, 1987, 1016 (In Bahasa Indonesia).

5. Chen TC, Ju YH. Polyunsaturated fatty acid concentrates from Borage and Linseed Oil fatty acids. Journal of American Oil Chemists' Society 2001; 485488.

6. Arcos JA, Garcia HS, Hill GG. Regioselective analysis of the fatty acid compositions of triacylglyceroles with conventional high-performance liquid chromatography. Journal of American Oil Chemists' Society 2000; 77: 507-512.

7. American Oil Chemists' Society. Official methods and recommended practices of the American Oil Chemists' Society. Edn 4, AOCS Press, 1997, Champaign.

8. Bockisch M. Fats and Oil Handbook. AOCS Pres, Champaign, 1998, 803-805.

9. Shahidi F. Bailey's industrial oil and fat products: Edible oil and fat products: specialty oils and oil products. Edn 6, Wiley-interscience, Canada, 2005, 175-188, 1543.

10. Dubois V, Breton S, Linder M, Fanni J, Parmentier M. Fatty acid profiles of 80 vegetable oils with regard to their nutritional potential. European Journal Lipid Science Technology 2007; 109: 710-732.

11. Osborn HT, Akoh CC. Structured lipids-Novel fats with medical, nutraceutical, and food applications. Comprehensive Reviews in Food Science and Food Safety 2002; 3: 110-120.

12. Bruckner G. Fatty acids and cardiovascular disease. In: Chow CK, ed., Fatty Acids in Foods and Their Health Implication. Edn 3, CRC Press, Boca Raton, 2008, 1069.

13. Massimo C, Lucio T, Jesus MA, Giovanni L, Gluseppe C. Extra virgin olive oil and oleic acid. Nutricion Clinica Dietetica Hospitalaria 2009; 29(3): 12-24.

14. Vemuri M, Kelley DS. The effects of dietary fatty acids on lipid metabolism. In: Chow CK, ed., Fatty acids in Foods and Their Health Implications. Edn 3, CRC Press, Boca Raton, 2008, 591-597.

15. Gurr MI, Harwood JL, Frayn KN. Lipid Biochemistry. Edn 5, Blackwell Science Ltd, United Kingdom, 2002, 160. 
16. Munio MDM, Esteban L, Robles A, Hita E, Jimenez MJ, Gonzalez PA, Camacho B, Molina E. Synthesis of 2-monoacylglycerols rich in polyunsaturated fatty acids by ethanolysis of fish oil catalyzed by 1,3 specific lipases. Process Biochemistry 2008; 43: 1033-1039.

17. Diwakar BT, Dutta PK, Lokesh BR, Naidu KA. Physicochemical Properties of Garden Cress (Lepidium sativum L.) seed oil. Journal of American Oil Chemists' Society 2010; 87: 539-548.

18. Azlan A, Prasad KN, Khoo HE, Abdul-Azis N, Mohamad A, Ismail A, Amom Z. Comparison of fatty acids, vitamin $\mathrm{E}$ and physicochemical properties of Canarium odontophyllum Miq.(Dabai), olive and palm oils. Journal of Food Composition and Analysis 2010; 23: 772-776.
19. Sitompul JP, Istyami AN, Muhtadi R, Kurnianto RW, Lee HW, Rahman H, Lee HW. Production of methyl laurate from coconut cream through fractionation of methyl ester. Journal of Engineering and Technological Sciences 2015; 47(5).

20. Aftab AK, Mahesar SA, Khaskheli AR, Sherazi, STH, Sofia Q, Zakia K. Gas Chromatographic coupled mass spectroscopic study of fatty acids composition of Nigella sativa L. (KALONJI) oil commercially available in Pakistan. International Food Research Journal 2014; 21(4): 1533-1537.

21. Ariponnammal S. A novel method of using refractive index as a tool for finding the adultration of oils. Research Journal of Recent Sciences 2012; 1(7): 77-79. 